\title{
O planejamento didático na atuação de pedagogas do Serviço de Convivência e
}

\section{Fortalecimento de Vínculos em João Pessoa-PB}

\section{DIAS, Luciana Silva (João Pessoa, Paraíba, Brasil) ${ }^{1^{*}}$}

SEVERO, José Leonardo Rolim de Lima (João Pessoa, Paraíba, Brasil) ${ }^{2^{* *}}$

1 Universidade Federal da Paraíba, Programa de Pós-Graduação em Educação, Mestrado em Educação

2Universidade Federal da Paraíba, Programa de Pós-Graduação em Educação, Centro de Educação

ORCID ID: https://orcid.org/0000-0001-9799-8628*

ORCID ID: https://orcid.org/0000-0001-5071-128X*

\section{Resumo}

Este artigo tem o objetivo de discutir os significados atribuídos pelas pedagogas do Serviço de Convivência e Fortalecimento de Vínculos, na cidade de João Pessoa, Paraíba, sobre o processo de planejamento didático que desenvolvem em seu cotidiano socioeducativo. $O$ artigo se baseia em uma pesquisa que possuiu uma abordagem qualitativa de inspiração no enfoque do interacionismo simbólico. Para a coleta dos dados, aplicaram-se questionários estruturados junto a 15 pedagogas que integram o referido serviço em João Pessoa. Para a apreciação dos dados, recorreu-se à análise de conteúdo. Pôde-se perceber que o planejamento faz parte do cotidiano das profissionais pesquisadas, com ênfase no marco técnico-operacional do Serviço de Convivência e Fortalecimento de Vínculos e em interesses destacados pelos(as) educandos(as). A dimensão política relativa ao sentido social da ação que planejam se apresenta de modo pouco evidente, o que pode levar à perda de potência transformadora das práticas de Educação Social no Serviço de Convivência e Fortalecimento de Vínculos.

\section{Palavras-chave}

Didática. Planejamento didático. Educação Social.

\section{The didactic planning in the performance of pedagogues from the Service of Coexistence and Strengthening of Bonds in João Pessoa-PB}

\begin{abstract}
This article aims to discuss the meanings attributed by the pedagogues from the Service of Coexistence and Strengthening of Bonds, in the city of João Pessoa, Paraíba, about the didactic planning process that they develop in their socioeducational routine. The article is based on research that had a qualitative approach inspired by the focus on symbolic interactionism. For data collection, structured questionnaires were answered by 15 educators who are part of the service in João Pessoa. To analyze the data, content analysis was used. It was possible to realize that planning is part of the daily life of the professionals surveyed, with an emphasis on the technical-operational framework of the Service of Coexistence and Strengthening of Bonds and on interests highlighted by the students. The political dimension related to the social meaning of the action they plan is not very evident, which can lead to the loss of transformative power of Social Education practices in the Service of Coexistence and Strengthening of Bonds.
\end{abstract}

\section{Keywords}

Didactics. Didactic planning. Social Education. 


\title{
Planificación didáctica en la actuación de pedagogas en el Servicio de Convivencia y Fortalecimiento de Enlaces en João Pessoa-PB
}

\begin{abstract}
Resumen
Este artículo tiene como objetivo discutir los significados atribuidos por las pedagogas del Servicio de Convivencia y Fortalecimiento de Enlace en la ciudad de João Pessoa, Paraíba, sobre el proceso de planificación didáctica que desarrollan en su cotidiano socioeducativo. El artículo se basa en una investigación que adoptó un enfoque cualitativo inspirado en el enfoque del interaccionismo simbólico. Para la recolección de datos, se aplicaron cuestionarios estructurados a 15 educadores que forman parte del servicio en João Pessoa. Para analizar los datos, se utilizó el análisis de contenido. Fue posible percibir que la planificación es parte de la vida cotidiana de los profesionales encuestados, con énfasis en el marco técnico-operativo del Servicio de Convivencia y Fortalecimiento de Bonos y en los intereses destacados por los estudiantes. La dimensión política relacionada con el significado social de la acción que planean no es muy evidente, lo que puede conducir a la pérdida del poder transformador de las prácticas de Educación Social en el Servicio de Convivencia y Fortalecimiento de Enlaces.
\end{abstract}

\section{Palabras clave}

Didáctica. Planificación. Educación Social.

\section{Introdução}

A Política de Assistência Social no Brasil é responsável por ofertar a proteção social e serviços específicos para atender às diferentes famílias na superação da vulnerabilidade social e prevenção de situações de risco (BRASIL, 1993). Sendo assim, o Serviço de Convivência e Fortalecimento de Vínculos (SCFV) caracteriza-se como um serviço de âmbito nacional de proteção social básica complementar ao Programa de Atenção Integral à Família (Paif), apresentando um caráter preventivo, protetivo e proativo, objetivando prevenir e proteger os(as) usuários(as) de riscos e violações de direitos e contribuir para o fortalecimento de vínculos familiares e comunitários (BRASIL, 2009b).

O SCFV surgiu em detrimento de um reordenamento feito pelo Ministério de Desenvolvimento Social (MDS) com o objetivo de unificar regras que envolvem serviços como o Programa de Erradicação do Trabalho Infantil (Peti), o Programa Nacional de Inclusão de Jovens (ProJovem), bem como aqueles que envolvem o público idoso, de forma que os recursos destinados a esses programas fossem unificados. O SCFV objetiva a integração dos sujeitos em estruturas participativas da sociedade, por meio de 
práticas socioeducativas que estimulem o desenvolvimento crítico, político e social desses sujeitos agrupados em ciclos de vida (BRASIL, 2009b).

Geralmente os grupos que fazem parte do SCFV se reúnem no Centro de Referência em Assistência Social (Cras) ou em outras instituições socioeducativas referenciadas a ele. Nessas instituições, os(as) educadores(as) planejam atividades e estratégias que possibilitem criar situações de diálogos, resoluções de conflito, participação social, construção de projetos de vida, valorização da diferença, conhecimento de direitos e deveres, etc. Trata-se de atividades que podem contribuir com a formação crítica desses usuários ou podem, numa outra perspectiva, centrar-se apenas no assistencialismo e minimização de conflitos sem contribuir com a transformação social.

$\mathrm{Na}$ perspectiva de Educação Social crítico-progressista (SEVERO, 2017), o SCFV pode desenvolver um trabalho comunitário muito importante e complexo para contribuir na melhoria da qualidade de vida dos(as) educandos(as), família e comunidade, colaborando para a superação das suas vulnerabilidades sociais. Isso demanda uma equipe bem qualificada para o sucesso de tais objetivos.

Refletir sobre o significado de planejamento é uma condição indispensável para entender as concepções que os(as) educadores(as) constituem, que se traduzem em seu modo de agir com os coletivos do SCFV e no conhecimento das estratégias usadas na compreensão do problema ou situação.

Acredita-se que não há ensino sem planejamento, porque esse processo exige responsabilidade e intencionalidade, embora seja ingênuo pensar que o planejamento por si só garantirá o sucesso do ensino, mas, sem este, perdem-se os detalhes e a variedade dos aspectos envolvidos. Sobre essa temática, Padilha (2001, p. 30) afirma: "[...] o ato de planejar é sempre um processo de reflexão, de tomada de decisão sobre a ação, de previsão de necessidades e racionalização do emprego de meios necessários para a concretização de objetivos". Percebe-se que vai muito além de uma prática de burocratização como elaborar planos ou programas e colocá-los em execução; é um processo de desenvolvimento da própria práxis pedagógica.

Através de uma busca no portal de periódicos da Coordenação de Aperfeiçoamento de Pessoal de Nível Superior (Capes) e na Biblioteca Digital Brasileira de Teses e Dissertações (BDTD), por meio dos descritores "Educação e Serviço de Convivência e Fortalecimento de Vínculos", "Práticas Educativas e Serviço de 
Convivência e Fortalecimento de Vínculo", Dias e Severo (2018) apontam que, entre cinco trabalhos recuperados por esses descritores, nenhum abordava a prática do planejamento didático, mas analisavam impactos de práticas artísticas (teatro, dança, capoeira e música) e o lazer no processo de integração e fortalecimento de vínculos.

A reflexão proposta neste artigo pretende evidenciar a importância de investimento acadêmico em estudos que desvelem novas formas de planejamento didático em espaços não escolares, possibilitando a construção de um marco teórico-metodológico que direcione as ações dos(as) educadores(as) sociais de maneira sistemática e reflexiva. Por conseguinte, acredita-se que a didática pode contribuir para melhorar os processos de ensino e aprendizagem desenvolvidos na Educação Social.

\section{Percurso metodológico}

A pesquisa segue uma abordagem qualitativa, pautando-se na interpretação do pesquisador e da pesquisadora como uma relação sistemática e ao mesmo tempo dinâmica com o objeto (SAMPIERI; COLLADO; LUCIO, 2013). O delineamento metodológico foi respaldado pelo interacionismo simbólico, fundamentado em Blumer (1980) e Mead (1977), perspectiva epistemológica que reforça a importância científica dos significados atribuídos pelos sujeitos, compreendendo-os não como fruto de uma atividade cognitiva isolada, mas sim como construídos por meio das relações sociais e culturais entre os sujeitos. Logo, essas relações são constitutivas do/no trabalho como processo de interação entre pessoas, contextos e culturas institucionais. Na lógica do interacionismo simbólico, a perspectiva dos sujeitos é tomada como objeto de análise da pesquisa, de modo que o sujeito social é visto como um agente crítico capaz de interpretar e construir seu mundo social a partir de suas interações com os outros (BLUMER, 1980).

Os participantes que compõem a pesquisa foram 15 pedagogas que trabalham em unidades do SCFV em João Pessoa, Paraíba (PB). As participantes foram informadas dos procedimentos éticos em conformidade com as orientações da Resolução № 466/2012, do Conselho Nacional de Saúde (CNS), manifestando seu consentimento livre e esclarecido. A pesquisa foi aprovada pelo Comitê de Ética em Pesquisa do Centro de Ciências da Saúde da Universidade Federal da Paraíba (UFPB) sob o número 3.191.518. 
As pedagogas tiveram suas identidades preservadas, assim como suas unidades de trabalho, sendo chamadas de pedagogas $1,2,3$, e assim sucessivamente.

Os dados foram coletados através de um questionário estruturado com questões objetivas. A aplicação foi realizada em uma oficina de formação continuada no dia 30 de novembro de 2018, promovida pelo projeto de extensão "Oficinas de Pedagogia Social no SCFV", desenvolvido no âmbito do Grupo de Estudos e Pesquisas em Pedagogia, Trabalho Educativo e Sociedade (Gepptes), na UFPB. Esse projeto objetivou colaborar com a realização de ações formativas para educadores(as) sociais e equipes gestoras que atuam no SCFV do município de João Pessoa-PB.

A apreciação dos dados foi realizada com arrimo na análise categorial de conteúdo, por meio da qual o pesquisador trabalha com as unidades de textos, formando categorias temáticas que ajudam a explorar e explicar melhor o corpus textual, confrontando-o com os objetivos da pesquisa e posteriormente analisando-o (BARDIN, 2011).

\section{Referencial teórico}

Acredita-se que refletir sobre a dimensão didática do planejamento é importante para a formação dos(as) educadores(as) que atuam ou almejam atuar nos espaços não escolares, onde se inclui o SCFV. O planejamento é um exercício de pensamento analítico-estratégico e exige uma reflexão sobre a realidade, sobre suas práticas, porque se trata de uma preparação reflexiva e antecipada de uma ação a fim de atingir determinados objetivos. Vasconcellos (1995) explica que o objetivo principal do planejamento é possibilitar um trabalho mais significativo e transformador. É de suma importância que o(a) educador(a) planeje suas ações de maneira consciente, crítica e intencional, com disposição e compromisso com a prática educativa.

No Brasil, a Educação Social surge através de ações socioeducativas com iniciativas de trabalho com crianças e adolescentes pobres, em condições de abandono, violência, visando à superação dessas circunstâncias e à garantia de seus direitos sociais (MACHADO, 2014), tendo como objetivo "[...] contribuir para a integração social do indivíduo estimulando a capacidade crítica, para que consiga melhorar e transformar o meio social em que vive" (CASTELEIRO, 2008, p. 5). Para isso, trabalha com a 
concepção de educação ampla, considerando o processo de interação social em que os indivíduos estão inseridos; nasce para sistematizar a educação social e garantir os direitos sociais de todos os cidadãos.

Essa educação acontece em espaços educativos diversos e é subsidiada pela política de assistência social, ou seja, nos espaços e serviços estruturados por essa política, cuja característica principal é reforçar a proteção social por meio de ações específicas para atender aos diferentes coletivos em situações de vulnerabilidade social e risco social. As práticas educativas desenvolvidas nesses espaços socioassistenciais podem ser consideradas como manifestação da Educação Social e precisam ser investigadas e valorizadas, de modo que seu caráter formativo seja problematizado quanto às possibilidades de promoção da transformação social. Acredita-se que é necessária uma didática que conduza a prática pedagógica da Educação Social para a promoção da reflexão/ação que proporcionem uma efetiva mediação dos processos de ensino e aprendizagem nos(as) envolvidos(as) (SEVERO, 2018).

A didática historicamente é vinculada à educação escolar, mas isso não significa que a escola seja o único espaço de formação e desenvolvimento do ensino e da aprendizagem. Nesse sentido, entende-se que a didática pode abarcar os processos socioeducativos preconizados pela Educação Social para que realmente promovam uma educação crítica e emancipatória.

Conforme Pimenta (1998), o objeto de investigação da didática é o ensino, entendido como uma prática social; não há incoerência em interpretar que a didática pode perpassar por outros espaços, não se tratando de reproduzir a forma escolar, e sim de criar possibilidades de diálogos para melhorar os processos socioeducativos, compreendendo que essas ações visam desenvolver o indivíduo no sentido global e provocar condições de participação destes como atores de sua própria história, aspectos essenciais de uma prática de Educação Social (SEVERO, 2018).

Dessa forma, acredita-se que toda educação deveria ser social, já que não pode ser limitada apenas a um período da nossa vida e não se fecha quando a pessoa deixa de frequentar a escola. Pelo contrário, ela nos acompanha ao longo da vida. Observa-se que a socialização do indivíduo acontece em lugares diversificados, e não apenas dentro da escola. Diante disso, é importante esclarecer que não existe apenas uma única maneira de entender a Educação Social. Para Casteleiro (2008), a Educação Social na 
atualidade é resultado de políticas sociais e é marcada por contextos específicos em cada país, por isso a sua compreensão também pode ser ampla e diversificada.

Segundo Imbernón (2010), a formação inicial e continuada de educadores(as) está fortemente condicionada à organização da instituição educacional e ao pensamento educacional único predominante (currículo igual, gestão idêntica, formação igual para todos, etc.), desconsiderando as outras formas de ensinar, de se organizar, de apreciar outras identidades culturais e sociais. O autor dirige a crítica mais especificamente à formação docente. Todavia, pode ser problematizada e direcionada nas discussões da formação dos(as) educadores(as) sociais, porque não tem como pensar na Educação Social de maneira homogênea; os contextos e sujeitos das práticas educativo-sociais são complexos e plurais, demandando saberes e habilidades amplas, bem como perfis de educadores(as) bastante diversificados.

Pérez-Gómez (2007) explica a importância de considerar o processo de formação e desenvolvimento profissional do(a) educador(a) em relação aos diferentes modos de conceber a prática educativa. Dessa forma, cita as três perspectivas ideológicas presentes:

I - A perspectiva tradicional, que concebe o ensino como uma atividade artesanal e o professor/a, como um artesão. II - A perspectiva técnica, que concebe o ensino como uma ciência aplicada e o docente, como um técnico. III A perspectiva radical, que concebe o ensino como uma atividade crítica e o docente, como um profissional autônomo que investiga refletindo sobre sua prática. (PÉREZ-GÓMEZ, 2007, p. 353).

A terceira perspectiva destaca a reflexão na prática para a reconstrução social. O ensino é concebido como uma atividade crítica e o(a) educador(a) é concebido como um profissional que reflete criticamente sobre a prática cotidiana para compreender os processos de ensino e aprendizagem, bem como o contexto social em que o ensino ocorre. Essas características são indispensáveis para se realizar uma educação emancipatória. Assim, busca-se desenvolver uma consciência social dos cidadãos para a construção de uma sociedade mais justa e igualitária, combatendo a injustiça social.

Para tanto, o planejamento é uma dimensão didática indispensável no trabalho pedagógico, visando constituir razões e modos de ação para a organização dos processos de ensino e aprendizagem compatíveis com esse pressuposto crítico-progressista de educação. Do mesmo modo que o planejamento deve fazer parte do cotidiano dos(as) 
profissionais que atuam com a educação escolar, é pertinente que essa prática seja pensada ou ressignificada para outros espaços educativos. Não se trata de reproduzir os modelos de planejamento desenvolvidos no âmbito escolar ou negá-los, mas de (re)criar um planejamento que viabilize uma intervenção sociopedagógica consistente; um planejamento que seja vivo e não se reduza a um plano ou uma atividade burocrática.

Padilha (2001, p. 30) afirma que "[...] o ato de planejar é sempre um processo de reflexão, de tomada de decisão sobre a ação, de previsão de necessidades e racionalização do emprego de meios necessários para a concretização de objetivos". Assim, esse processo vai muito além de uma prática de burocratização que se expressa na elaboração de planos ou programas que se deseja e executá-los, muitas vezes sob uma lógica hierárquica que dissocia quem planeja e quem executa. Compreende-se que o planejamento é um processo de desenvolvimento da própria práxis pedagógica.

Para Pérez Serrano (2004, p. 274), "[...] planejar é desenhar os planos para a execução de um trabalho; fazer um plano ou projeto de uma ação, antecipar a ação" para dar uma resposta antecipada e sistemática às necessidades socioeducativas. $O$ sucesso das atividades no SCFV corresponde, dentre outros fatores, a um bom planejamento. Porém, é importante deixar claro que o planejamento deve ser sempre flexível, por isso deve ser modificado quando as circunstâncias exigirem. Com efeito, não é porque se planeja que se tem o resultado positivo garantido na intervenção socioeducativa, mas o conhecimento prévio e a visão estratégica de cada situação ajudam a enfrentar imprevistos e a qualificar a tomada de decisões.

Gandin (1994) aponta dois níveis de planejamento: o primeiro é o nível operacional (dimensão técnica), que visa responder ao "como" e "com quê", tratando dos meios, tempo, recursos e técnicas de maneira isolada; nesse sentido, busca-se a eficiência e limita-se ao curto prazo; o segundo é o nível político (dimensão política), que busca responder ao "para quem", "para quê", incluindo "o quê", sendo mais amplo por tratar dos fins, do sentido e da expectativa de impacto. Nota-se que a dimensão técnica e a dimensão política são interdependentes e juntas dão sentido e vitalidade ao planejamento. Quando são tomadas como sendo antagônicas, geralmente revelam uma relação de poder e intenções camufladas, limitando a compreensão da realidade. Luckesi (1992, p. 32) "[...] propõe que o planejamento é um ato ao mesmo tempo político-social, científico e técnico pelo qual se projetam fins e se estabelecem meios para atingi-los". 
Os profissionais do SCFV trabalham com sujeitos em situação de vulnerabilidade e exclusão social e se deparam com problemas de natureza complexa que exigem uma reflexão crítica sobre a intencionalidade das políticas que constroem seu contexto de trabalho, atentando para que "[...] a atividade de planejar, sem que se esteja atento aos seus significados ideológicos, é um modo - dentre muitíssimos outros - de resguardar o modelo de sociedade ao qual serve esse planejamento" (LUCKESI, 1992, p. 118). É imprescindível pensar nas questões políticas e sociais envolvidas na definição e operacionalização das políticas sociais, problematizando seus objetivos e estratégias de ação, aspectos cruciais do planejamento reflexivo.

\section{Resultados e discussões}

Sob a premissa de que o interacionismo simbólico tem como ponto de partida empírico os significados atribuídos pelos indivíduos nas suas atividades cotidianas, busca-se dialogar com os dados extraídos dos questionários aplicados junto às pedagogas que trabalham no SCFV na cidade de João Pessoa-PB. No que tange ao tempo de serviço, todas tem mais de quatro anos de experiência. Essas pedagogas trabalham com as crianças, adolescentes e idosos(as) atendidos pelo SCFV, desempenhando a função de técnicas ou educadoras sociais.

As categorias temáticas que fundamentaram a elaboração dos questionários foram: planejamento didático, Educação Social e práticas pedagógicas não escolares. Essas categorias ajudaram no momento de recorte das respostas presentes nos questionários. Dessa forma, analisaram-se os questionários qualitativamente, por isso o índice é indispensável, porque é mais importante a relevância da interpretação do tema presente nas respostas do que a frequência ou repetição do tema (BARDIN, 2011). Elaborou-se o questionário estruturado com base nos seguintes itens: "Para você, o que é planejar?"; "Com qual periodicidade você planeja as atividades?"; "Você utiliza instrumentos individuais ou coletivos?"; "Quais os recursos didáticos utilizados para desenvolver as ações educativas?".

Por meio dos dados colhidos através do questionário estruturado, verificou-se um consenso entre as pesquisadas sobre o significado de planejamento, apontado como um processo técnico para prever, antecipar e organizar as ações, dando a entender que 
não requer uma reflexão e problematização dos efeitos políticos que envolvem as tomadas de decisões sobre as ações planejadas. Ficou explícita a dimensão técnica presente nas seguintes definições:

\footnotetext{
Planejar é antecipar, preparar e elaborar conteúdos e práticas a ser aplicadas nas atividades diárias. (PEDAGOGA 1).

É elaborar as atividades previamente para que sejam bem desenvolvidas. (PEDAGOGA 3)

É resumir toda a sua semana ou mês numa agenda para que facilite seu trabalho com os jovens. (PEDAGOGA 11).
}

Organizar antecipadamente metas, avaliar, construir estratégias, levando em consideração o todo. (PEDAGOGA 13).

Organizar conteúdos e sistematizar atividades com antecedência. (PEDAGOGA 15).

Mediante esses trechos, observou-se que o significado se expressa na ênfase dada à dimensão técnica do planejamento, em que prever, antecipar e organizar as ações parecem prescindir da construção de objetivos com base na problematização dos efeitos políticos que envolvem as tomadas de decisões sobre as ações planejadas. A dimensão técnica é importante, porém não se pode suprimir as dimensões política e social.

Desse modo, como menciona Lück (2014), o planejamento é fruto de decisões que precisam ser tomadas de maneira crítica, as quais são pautadas no compromisso político, de modo a contribuir com a transformação da realidade. Não se trata de agir por agir, mas de refletir sobre cada decisão, de se comprometer com a dimensão política inerente ao processo de planejamento.

As pedagogas assinalaram que baseiam o planejamento em documentos orientadores e normativas do SCFV, considerando as necessidades apresentadas pelos(as) educandos(as), como se pode identificar nos seguintes depoimentos:

São elaborados através da observação e conhecimento das realidades nas quais atuamos, unindo a intencionalidade do trabalho. (PEDAGOGA 4).

Baseados em normativas legais do serviço e demandas da comunidade. (PEDAGOGA 6).

A partir dos assuntos expostos pelos educandos que querem trabalhar, procuro atividades e vejo quais objetivos podem ser trabalhados. (PEDAGOGA 11). 
Eles são criados a partir das necessidades apresentadas pelos educandos, famílias, comunidade, sociedade, e por sugestões de atividades que eles trazem. (PEDAGOGA 12).

A Pedagoga 11 ressaltou que elabora os objetivos do seu planejamento através das necessidades dos(as) estudantes. Já a Pedagoga 12 acrescentou família, comunidade e sociedade. Essa etapa de previsão de necessidades é denominada por Gandin (2001) como diagnóstico, momento em que se faz uma intermediação entre o ideal desejado e as necessidades existentes. As propostas de ação para superação dessas necessidades exigem um processo de decisão constante e uma dinâmica de ação e reflexão que, embora não estejam explícitas nas concepções de planejamento apresentadas pelas pedagogas, são percebidas claramente na elaboração dos objetivos do planejamento.

Conforme as normativas do serviço, as temáticas que orientam as oficinas estão relacionadas às áreas: infância/adolescência, direitos humanos e socioassistenciais, saúde, meio ambiente, cultura, esporte, lazer, ludicidade, brincadeira e trabalho (BRASIL, 2009a). São áreas que exigem uma reflexão crítica para uma coerência dos objetivos.

Os objetivos centrais estão na elaboração das oficinas, onde ocorrem trocas, debates com os usuários. Então, os objetivos da minha prática giram em torno do refletir e conhecer. Refletir sobre o mundo, o contexto em que está inserido e o que mais surgir; conhecer é ter contato com coisas novas, principalmente lugares novos; aumentar o repertório. (PEDAGOGA 3).

Essa participante destacou que os objetivos giram em torno das oficinas trabalhadas, sendo organizados de acordo com a faixa etária dos grupos. Com relação aos profissionais que atuam dentro do SCFV, é importante que estes reflitam e (re)criem os objetivos, em vez de simplesmente reproduzir as propostas nos documentos. Isso será possível na medida em que o planejamento for um espaço de diálogo com os(as) educandos(as), inclusive porque essa relação fortalece os vínculos educativos, tornando a relação horizontal e estimulando a participação dos usuários nas atividades de modo mais produtivo e prazeroso (DÍAZ; SANTOS, 2014).

Ao serem indagadas sobre a periodicidade com que planejam as atividades desenvolvidas no SCFV, dez pedagogas responderam que semanalmente e cinco, diariamente. É essencial que se reserve um tempo para a prática de planejar, todavia o planejamento não é um momento que se divide em dias, semanas, meses ou anos, é um processo que exige desdobramento contínuo ao longo das atividades, como uma 
dimensão permanente de organização do trabalho pedagógico junto a todos os(as) envolvidos(as) (LÜCK, 2014).

Mais importante do que a frequência é a reflexão sobre como esse processo de planejamento acontece, se é tomado como uma atividade técnica ou formal que serve apenas para legitimar o seu trabalho junto aos superiores, ou se realmente é utilizado de maneira crítica (DIAS; SEVERO, 2018).

Quando questionadas sobre os recursos didáticos que costumam usar, as pedagogas relataram: "Livros, revistas, vídeos, jogos, documentários/filmes/vídeos, músicas, poemas e textos, papéis, Datashow, caneta, lápis, cola, tintas, pincéis, computador, celular, bambolês, cordas, bastões, material gráfico e jogos, entre outros materiais" (PEDAGOGAS 1, 2, 3).

Observou-se a variabilidade de materiais como recursos didáticos, mas a ausência de outros elementos mais ligados às tecnologias, por exemplo, tendo sido citados, genérica e isoladamente, "celular" e "computador". Isso se explica pela precariedade do financiamento do SCFV, segundo a Pedagoga 15, mas também se pode inferir que tal limitação pode ser explicada pela dificuldade de incorporar na cultura didática as tecnologias da informação e comunicação, incluindo redes sociais, assim como na escola essa limitação também se expressa. Porém, tampouco a simples incorporação sem sentido pedagógico de uso traria impactos significativos no planejamento e nas práticas didáticas. Os materiais didático-pedagógicos, quando planejados, são instrumentos que auxiliam o trabalho pedagógico do educador e da educadora. Assim, entende-se que os recursos didáticos ganham relevância conforme o potencial que possuem para mobilizar interesses e capacidades de aprendizagem de educadores(as) e educandos(as). Utilizar materiais sem prévia reflexão e desvinculados dos objetivos não garante sucesso na aprendizagem.

Os recursos devem ser pensados sempre de maneira crítica e multidimensional, isso é resultado de uma organização didática crítica que contempla todas as etapas da prática educativa enraizada em contextos (objetivos, planejamento, recursos, metodologia, avaliação). O uso de um recurso inovador dissociado de um sentido pedagógico de aprendizagem ativa dos(as) educandos(as) leva a pensar que a qualidade do recurso está em como se situa na organização didática do processo formativo para a construção de saberes e atitudes relativas às finalidades do trabalho no SCFV. 
Quando questionadas sobre o uso do planejamento individual ou coletivo, a resposta das pedagogas foi unânime ao informar que utilizam o coletivo. Os trechos abaixo exemplificam as respostas:

Reuniões semanais para discutir, planejar e organizar. (PEDAGOGA 3).

Reunião para elaborar as atividades da semana. (PEDAGOGA 9).

Reuniões semanais com técnicas de referência e orientadores para elaborarmos os assuntos que vão ser apresentados em sala com o SCFV. (PEDAGOGA 11).

Sempre fazemos planejamento coletivo, usando os temas sugeridos pela secretaria. (PEDAGOGA 14).

Gandin (1994) defende uma proposta de planejamento participativo baseada no trabalho coletivo, que possui metodologia e estratégias próprias, em que os membros desenvolvem um pensamento grupal. Contudo, esse pensamento é resultado de um processo anterior, no qual é necessário que cada pessoa se pronuncie, expondo seu posicionamento pessoal, para então sair da esfera individual para a grupal. Essa dimensão deve ser estimulada no SCFV, pois a complexidade dos objetivos e formas de enfrentamento aos desafios sociais nos territórios em que os(as) educadores(as) atuam exige um trabalho colaborativo que se consolide como traço definidor da ação sociopedagógica das instituições, através de uma cultura de troca e suporte mútuo no planejamento, desenvolvimento e avaliação de processos.

Outra questão feita relacionou-se com as dificuldades que encontram para efetivar o planejamento. As respostas se concentraram em dois pontos: falta de recursos materiais e falta de capacitação.

Nossa maior dificuldade é com relação à quantidade e qualidade dos recursos materiais; também com relação à falta de internet no Cras para pesquisa e aos recursos para transmissão dos filmes, vídeos. (PEDAGOGA 5).

A falta de material disponível dificulta a execução das ações no cotidiano e restringe nossos avanços. (PEDAGOGA 7).

Falta capacitação para atuar no SCFV; na universidade só nos ensinaram a trabalhar na sala de aula. (PEDAGOGA 8).

Nos depoimentos das Pedagogas 5 e 7, percebe-se a carência de material didático para a realização das atividades; já a Pedagoga 8 apontou um problema em 
relação à formação, destacando que sente falta de capacitações e realçando que o curso de Pedagogia não the preparou para trabalhar nos espaços não escolares.

Sobre a questão da formação, as Diretrizes Curriculares Nacionais do curso de Pedagogia (BRASIL, 2006), prevê a inclusão dos espaços não escolares para a atuação do pedagogo(a), mas não está clara a maneira como este profissional vai ser formado e os princípios de atuação nesses diferentes espaços. Mesmo assim, considera-se que o currículo do curso de Pedagogia deve incorporar saberes e experiências para a formação do(a) pedagogo(a), de modo que esteja apto a atuar em espaços de educação não escolar.

Os cursos de Pedagogia precisam analisar e refletir sobre as práticas educativas desenvolvidas em sua multiplicidade de espaços e tempos, considerando demandas sociais de formação humana em uma sociedade de contradições, mas também de oportunidades pedagógicas. Como afirma Saviani (2007, p. 152), "[...] a pedagogia revela-se capaz de articular num conjunto coerente as várias abordagens sobre a educação, tomando como ponto de partida e ponto de chegada a própria prática educativa".

Posto isso, verifica-se que as pedagogas têm consciência do marco operacional, da importância da previsão das necessidades e das dificuldades que envolvem o processo do planejamento. Dessa forma, é importante que as pedagogas compreendam que planejar não é só organizar a realidade existente, isso é, apenas uma etapa operacionalizada. Em relação às concepções apresentadas pelas pedagogas sobre o planejamento, apesar de não problematizarem o marco político, fica evidente que o consideram no processo de elaboração dos objetivos, bem como a importância do diagnóstico da realidade e das necessidades apresentadas pelos educandos.

\section{Considerações finais}

Compreende-se que o planejamento é o processo pelo qual a prática educativa é concebida dentro de uma intencionalidade, projetado a fim de contribuir para a concretização dos objetivos. Essa projeção parte principalmente das necessidades reais de aprendizagem, que norteiam o momento do planejamento. Torna-se imprescindível determinar as finalidades educativas como operação que viabiliza transformar os 
objetivos em estratégias que envolvam conteúdos e a metodologia mais adequada. Assim, a formulação dos objetivos ajuda na elaboração da estratégia de ação.

Este artigo debruçou-se sobre a reflexão a respeito do planejamento didático na atuação das pedagogas que atuam no Serviço de Convivência e Fortalecimento de Vínculos (SCFV). A partir dos dados levantados, percebe-se que a ação de planejar está presente no cotidiano das profissionais pesquisadas. No entanto, observa-se uma dicotomia com relação ao entendimento das dimensões política e operacional do planejamento. O marco político está deslocado do contexto do planejamento, o qual se centra em aspectos operacionais ou no diagnóstico de interesses de educandos(as) concernentes a gostos ou inclinações. Conclui-se que há uma necessidade de ressignificação acerca dessa compreensão, considerando que a fragmentação dessas dimensões poderá refletir na execução do planejamento.

\section{Referências}

BARDIN, L. Análise de conteúdo. 70. ed. Lisboa: LDA, 2011.

BRASIL. Lei no 8.742, de 7 de dezembro de 1993. Dispõe sobre a organização da Assistência Social e dá outras providências. Diário Oficial [da] República Federativa do Brasil, Poder Executivo, Brasília, DF, 8 dez. 1993.

BRASIL. Norma Operacional Básica - NOB RH. Brasília, DF: Ministério do Desenvolvimento Social e Combate à Fome, 2009a.

BRASIL. Resolução CNE/CP no 1, de 15 de maio de 2006. Institui Diretrizes Curriculares Nacionais para o Curso de Graduação em Pedagogia, licenciatura. Diário Oficial [da] República Federativa do Brasil, Poder Executivo, Brasília, DF, 16 maio 2006.

BRASIL. Resolução no 109, de 11 de novembro de 2009. Aprova a Tipificação Nacional de Serviços Socioassistenciais. Diário Oficial [da] República Federativa do Brasil, Poder Executivo, Brasília, DF, 25 nov. 2009b.

BRASIL. Resolução no 466, de 12 de dezembro de 2012. Diretrizes e normas regulamentadoras de pesquisas em seres humanos. Diário Oficial [da] República Federativa do Brasil, Poder Executivo, Brasília, DF, 13 dez. 2012.

BLUMER, H. A natureza do interacionismo simbólico. In: MORTENSEN, C. (Org.). Teoria da comunicação: textos básicos. São Paulo: Mosaico, 1980. p. 119-138.

CASTELEIRO, S. Pedagogia social: aspectos essenciais e definitórios. 2008. Dissertação (Mestrado em Educação Social e Comunitária) - Programa de Pós-Graduação em Educação Social e Comunitária, Universidade da Beira Interior, Covilhã, 2008. 
DIAS, L. S.; SEVERO, J. L. R. L. Mapeamento de teses e dissertações sobre Pedagogia Social e Educação Social no contexto brasileiro. In: EPEN, 24., 2018, João Pessoa. Anais... João Pessoa: Universidade Federal da Paraíba, 2018.

DÍAZ, C. G.; SANTOS, L. S. La formulación de los objetivos instructivos en el contexto del currículo docente. Educación Médica Superior, La Habana, v. 28, n. 3, p. 467-481, 2014. Disponível em: http://www.ems.sld.cu/index.php/ems/article/view/279. Acesso em: 20 mar. 2020.

GANDIN, D. A posição do planejamento participativo entre as ferramentas de intervenção na realidade. Instituto Latino-Americano de Planejamento Participativo, Porto Alegre, v. 1, n. 1, p. 81-95, 2001. Disponível em: https://biblat.unam.mx/hevila/curriculosemfronteiras/2001/vol1/no1/4.pdf. Acesso em: 20 mar. 2020.

GANDIN, D. A prática do planejamento participativo. Petrópolis: Vozes, 1994.

IMBERNÓN, F. Formação continuada de professores. Porto Alegre: Artmed, 2010.

LÜCK, H. Planejamento em orientação educacional. 23. ed. Petrópolis: Vozes, 2014.

LUCKESI, C. C. Planejamento e avaliação na escola: articulação e necessária determinação ideológica. Ideias, São Paulo, n. 15, p. 115-125, 1992. Disponível em: http://professor.ufop.br/reginaaraujo/classes/edu-517-gest\%C3\%A3o-e-planejamentoescolar/materials/texto-06-planejamento-e. Acesso em: 20 mar. 2020.

MACHADO, É. R. O desenvolvimento da Pedagogia Social sob a perspectiva comparada: o estágio atual no Brasil e Espanha. 2014. 304 f. Tese (Doutorado em Educação) - Programa de Pós-Graduação em Educação, Universidade de São Paulo, São Paulo, 2014.

MEAD, G. H. O jogo livre (folguedo), o jogo regulamentado e o "outro-generalizado". In: BIRNBAUM, P.; CHAZEM, F. (Org.). Teoria sociológica. São Paulo: Hucitec: USP, 1977. p. $36-40$.

PADILHA, R. P. Planejamento dialógico: como construir o projeto político-pedagógico da escola. São Paulo: Cortez, 2001.

PÉREZ-GÓMEZ, A. I. A função e formação do professor/a no ensino para a compreensão: diferentes perspectivas. In: SACRISTÁN, J. G.; PÉREZ-GÓMEZ, A. I. (Org.). Compreender e transformar o ensino. 2. ed. Porto Alegre: Artmed, 2007. p. 353-379.

PÉREZ SERRANO, G. Elaboração de projectos sociais: casos práticos. 12. ed. Porto: Porto, 2014.

PIMENTA, S. G. Panorama atual da didática no quadro das ciências da educação: educação, pedagogia e didática. In: PIMENTA, S. G. (Coord.). Pedagogia, ciência da educação?. 2. ed. São Paulo: Cortez, 1998. p. 39-70.

SAMPIERI, R. H.; COLLADO, C. F.; LUCIO, P. B. Metodología de la investigación. 3. ed. México: McGraw Hill, 2010. 
SAVIANI, D. História das ideias pedagógicas no Brasil. Campinas: Autores Associados, 2007.

SEVERO, J. L. R. L. O horizonte da pedagogia social: uma perspectiva de aproximação conceitual. Revista Ibero-Americana de Estudos em Educação, Araraquara, v. 12, n. 4, p. 2122-2137, 2017.

SEVERO, J. L. R. L. Quando a didática frequenta outros espaços: indícios conceituais para abordagem de processos educativos não escolares. João Pessoa: Universidade Federal da Paraíba, 2018. p. 249-271.

VASCONCELLOS, C. S. Planejamento: plano de ensino-aprendizagem e projeto educativo. São Paulo: Libertad, 1995.
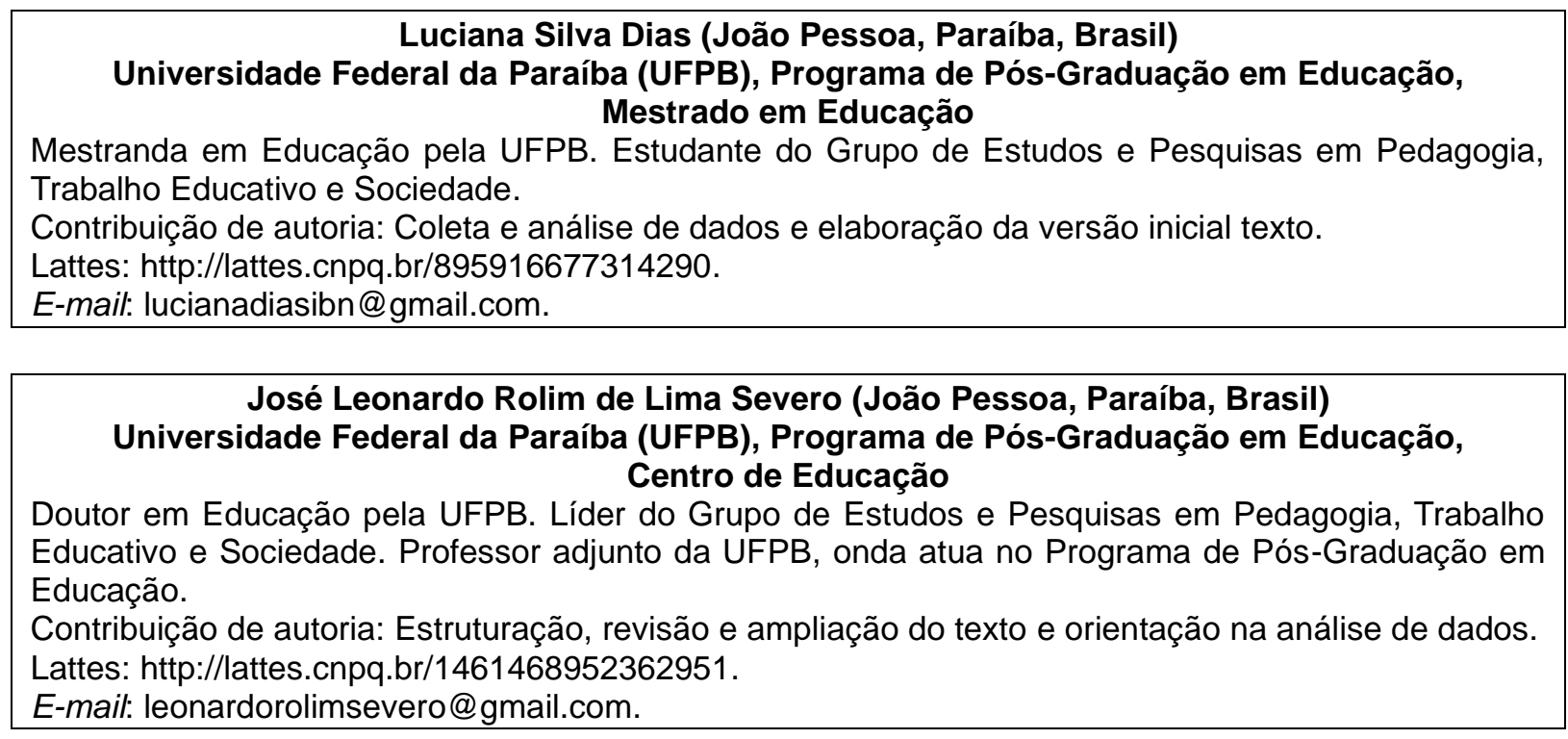

Editora responsável: Lia Machado Fiuza Fialho Pareceristas ad hoc: Ana Paula Silva e Karina Dias

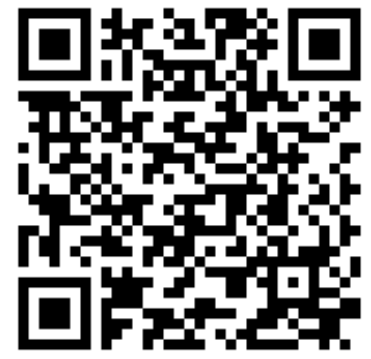

Recebido em 21 de agosto de 2019.

Aceito em 23 de janeiro de 2020. 